Data de recebimento do artigo: 18-11-2017

Data de aceite do artigo: $22-3-2018$

DOI: http://dx.doi.org/10.7769/gesec.v9i1.755

\title{
Produção sobre educação corporativa no Brasil: um estudo bibliométrico
}

\author{
Gustavo Sousa Toledo \\ Graduado em Administração pela Universidade Federal de Uberlândia (UFU). E-mail: \\ adm.gtoledo@gmail.com (Brasil)
}

\section{Carlos Roberto Domingues}

Doutor em Administração de Empresas pela EAESP/FGV. Professor Adjunto da Faculdade de Gestão e Negócios da Universidade Federal de Uberlândia (UFU).

E-mail: carlos.domingues@ufu.br (Brasil)

\section{RESUMO}

Este artigo tem como objetivo identificar e analisar a produção acadêmica sobre o tema "Educação Corporativa" nos últimos 20 anos. O procedimento metodológico utilizado foi a pesquisa bibliométrica. Para tanto, foram pesquisados os trabalhos acadêmicos através das plataformas portal Spell, periódicos Capes e nos periódicos ligados a Anpad, como a BAR - Brazilian Administration Review, a RAC - Revista de Administração Contemporânea, a TAC - Tecnlogia de Administração e Contabilidade e a RAC Eletrônica. E, a partir da análise dos dados, pode-se afirmar que a pesquisa vai ao encontro do que os principais autores do tema Educação Corporativa e Gestão de Pessoas têm apontado em suas obras contemporâneas, nas quais eles têm apontado que a educação corporativa e sua estrutura vêm deixando de ser meras coadjuvantes e desfrutadoras de recursos financeiros para, finalmente, terem seus valores estratégicos reconhecidos e assim serem geridas como tal. Os estudos reforçam, cada vez mais, que a gestão de pessoas, desde que bem definido seu papel e alinhamento com a estratégia da organização, pode gerar e aumentar o desempenho e a produtividade.

PALAVRAS-CHAVES: Educação corporativa. Gestão por competências. Treinamento e desenvolvimento. 
Toledo, G. S. \& Domingues, C. R. (2018).

\title{
Production on corporate education in Brazil: a bibliometric study
}

\begin{abstract}
We aimed to identify and to analyze the academic researches on the theme "corporate education" in the last 20 years. As methodological basis we used a bibliometric research in order to gather academic research from SPELL Electronic Library, Periódicos CAPES basis and journals from ANPAD like BAR Brazilian Administration Review, RAC - Revista de Administração Eletrônica, TAC - Tecnologia de Administração e Contabilidade and RAC - Eletrônica. According to data analysis, it is possible to confirm the authors' ideas on Corporate Education and The Human Resource Management which converges to corporate education and its structure have ceased to be mere supporting roles and recipient of financial resources to finally have their strategic values recognized and thus be managed as such. Studies increasingly emphasize Human Resource Management can increase performance and productivity since their role and alignment with the organization strategy is well-defined.
\end{abstract}

KEYWORDS: Corporate education. Competence management. Training and development.

\section{Como referenciar em APA:}

Toledo, G. S. \& Domingues, C. R. (2018). Produção sobre educação corporativa no Brasil: um estudo bibliométrico. R.G.Secr.,GESEC, 9(1). doi: http://dx.doi.org/10.7769/gesec.v9i1.755

\section{Como referenciar em ABNT:}

TOLEDO, G. S.; DOMINGUES, C. R. Produção sobre educação corporativa no Brasil: um estudo bibliométrico. $\quad$ R.G.Secr.,GESEC, $\quad$ v. $\quad 9, \quad$ n. 1, 2018. doi: http://dx.doi.org/10.7769/gesec.v9i1.755
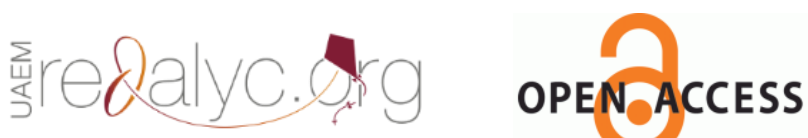

R.G. Secr., GESEC, São Paulo, v. 9, n. 1, p 108-127, jan./abr. 2018. 


\section{Introdução}

O tema educação sempre esteve nas pautas das pesquisas acadêmicas e nas pesquisas organizacionais. Em 1990, com o início da "Sociedade do Conhecimento", a qual se caracteriza pela interação de indivíduos que buscam a discussão e reflexão de assuntos de todas as áreas do conhecimento, ensinando e aprendendo entre si, com a geração de troca de informações nunca antes vista, a educação transforma-se em uma peça fundamental para que as organizações possam trabalhar com o grau de modernidade, inovação e competitividade que é exigido pela atual situação globalizada dos negócios.

Paralelo a isso, o setor de Treinamento e Desenvolvimento (T\&D) e a área de Gestão de Pessoas passavam por dificuldades, principalmente pela falta de credibilidade em relação às demais áreas da organização. Elas eram consideradas como ineficazes, e em alguns casos desnecessárias e de altos custos. Até o período dos anos de 1990, o que se trabalhava eram os conhecimentos técnicos e operacionais, competências e habilidades gerenciais. Porém, as atividades inerentes às estratégias não tinham espaço no modelo de T\&D.

$\mathrm{Na}$ revisão dessas práticas, abre-se espaço para um novo processo que é a educação corporativa. Seu objetivo estava ancorado na transformação de organizações tradicionais para naquelas que aprendem a aprender, por meio das técnicas de aprendizagem contínua que, por sua vez deveriam ser alinhadas às estratégias e objetivos dos negócios. Fatores como estratégia que antes eram ignorados, foram reconhecidos como indispensáveis, e que deveriam ser compreendidos em todos os níveis da estrutura, por meio de diferentes linguagens. Foi reconhecido que para um treinamento eficaz, devem-se fazer interações com a missão, objetivos e estratégias da organização, e assim apresentar resultados positivos (Eboli, 2002; Meister, 1999).

O contexto organizacional demandava por novas práticas de T\&D e, assim, a educação corporativa emergiu como uma nova e mais ampla dimensão do treinamento e desenvolvimento na medida em que a globalização tornava o mercado cada vez mais competitivo, mais exigente e que busca por diferenciais e vantagens competitivas, assim como a demanda pela agregação de valor aos negócios só aumentavam. Fez-se necessária a disseminação mais ágil e eficaz de informações e conhecimentos (Eboli, 1999; 2004).

O início da educação corporativa se deu pela implantação de programas de treinamentos gerenciais, o autogerenciamento da carreira e a autônoma. O gestor passou de agente passivo, que apenas acatava instruções, para agente ativo que toma decisões 
Toledo, G. S. \& Domingues, C. R. (2018).

confiantes, inovadoras, mais ágeis e eficazes. Para Eboli (1999; 2004), a educação corporativa veio para promover uma qualificação profissional que desse a capacidade ao indivíduo de entender, interpretar, interagir e compartilhar, estimulando a inovação, a criatividade, o empreendedorismo e o desenvolvimento de lideranças. Os modelos de educação corporativa no Brasil vêm evoluindo de maneira significativa nos últimos anos. Porém, segundo a autora, têm-se visto poucas iniciativas de pesquisa neste tema, o que justifica um estudo mais específico de como está sendo tratado o assunto nos últimos anos pela academia brasileira, especificamente, na área de Administração e afins.

Dado este cenário, a pergunta norteadora desta pesquisa pode ser assim apresentada: como se dá a produção dos últimos 20 anos a respeito do tema Educação Corporativa, especificamente Universidades Corporativas? Sabe-se que é mister identificar, descrever e analisar os elementos que a compõe, bem como sua relevância, haja vista que as mudanças decorrentes desta proposta de atuação da área afetarão não apenas a área de Gestão de Pessoas, mas a empresa como um todo. Assim, ao estruturar o que já foi produzido na forma de um levantamento bibliométrico pretendeu-se oportunizar, a quem tiver interesse em aprofundar-se no tema, um panorama da produção acadêmica brasileira e a sugestão de temas relevantes e promissores para pesquisas futuras.

Este estudo se caracteriza como de natureza descritiva, sob abordagem quantitativa, a partir do levantamento bibliográfico exclusivamente em artigos e livros. Foram pesquisados trabalhos acadêmicos nos periódicos e eventos da Associação Nacional de Pós-graduação e Pesquisa em Administração - Anpad - portal Spell, Enanpad, Eneo, BAR - Brazilian Administration Review, RAC - Revista de Administração Contemporânea, TAC - Tecnologia de Administração e Contabilidade e RAC Eletrônica) a respeito do tema Educação Corporativa. Para o levantamento e seleção dos trabalhos acadêmicos nos periódicos citados foram utilizadas as palavras-chave: Gestão de treinamento, treinamento e desenvolvimento, recursos de $\mathrm{T} \& \mathrm{D}$, treinamento e desenvolvimento gerencial, educação corporativa, aprendizagem organizacional, e gestão por competências.

A partir desse levantamento de dados, foi realizada a análise da produção tendo como variáveis: anos da publicação, títulos, autores, instituições de ensino, objetivos, palavraschave, periódicos, abordagens, tipos de pesquisa, objetivos (exploratório, descritivo ou explicativo), procedimentos técnicos, temas e subtemas, citações e obras utilizadas na 
produção deles. Todos esses pontos foram tabulados com o software Microsoft Excel e foram analisados com o uso da ferramenta tabela dinâmica.

Assim, o artigo está organizado considerando os seguintes elementos: introdução ao tema demonstrando a importância de um levantamento bibliométrico, em seguida, no referencial teórico empírico são abordados os principais elementos teóricos que envolvem a pesquisa, depois é feita a sustentação das escolhas metodológicas, na sequência são descritos os resultados e as análises e, por fim, é apresentada a conclusão.

\section{Referencial Teórico Empírico}

A partir dos anos de 1990, a gestão de pessoas e sua representatividade nas organizações sofreram constantes mudanças (Albuquerque \& Fischer, 2000) e, a partir desse momento, a área de gestão de pessoas e seus subsistemas começaram a ter seus papéis e atividades questionados. Assim, emergiu a questão: esta área desenvolve apenas um papel de apoio à administração ou ela é entendida como uma área que influencia diretamente a estratégia?

Com isso, criou-se um novo modelo, em que a gestão passa a ser trabalhada por meio da competência profissional, isto é, dar sentido ao trabalho desenvolvido na empresa por meio da capacidade em articular conhecimentos técnicos e gerenciais, habilidades e atividades realizadas dentro da organização. A gestão de pessoas passou a ter, então, uma nova concepção, criando-se um novo sistema para gerir pessoas (Albuquerque \& Oliveira, 2001)

Com o processo de globalização, o mundo dos negócios tem-se caracterizado pela sua volatilidade graças às constantes e profundas mudanças, logo, demanda por soluções e explicações cada vez mais rápidas e que levam a uma nova procura de perfis profissionais a serem contratados e mantidos. Perfil este que deve ser voltado para a aprendizagem contínua e para o autodesenvolvimento (Eboli, 2002).

Nesse contexto, a competitividade, a modernidade e a inovação, compatíveis com o que o atual mercado exige, passaram a desenvolver um papel indispensável. As organizações precisam construir sistemas de educação que estejam alinhados com a sua estratégia e assim desenvolver seus talentos humanos com eficiência e eficácia. $\mathrm{O}$ foco passou a ser as pessoas e não o processo produtivo, certificando o papel estratégico do primeiro neste novo contexto, em que o conhecimento é verdadeiramente o que importa. 
Toledo, G. S. \& Domingues, C. R. (2018).

Tal abordagem recai sobre a tese da educação corporativa, que de acordo com Meister (1999) é compreendida como o processo do conjunto ensino/aprendizagem contínuo que é engajado às estratégias, possibilitando o processo de constituição de competências que levarão à vantagem competitiva. A educação corporativa trouxe, assim, um novo aspecto do treinamento e desenvolvimento dentro das organizações, muito mais amplo e com o objetivo de agregar valor aos negócios.

Segundo Meister (1999) a expressão Educação Corporativa provém dos anos de 1950, quando nos Estados Unidos, empresas que estavam decididas a se tornarem líderes de mercado em seus determinados setores, estabeleceram a EC como uma atividade de gestão de pessoas para a busca e auxílio na competitividade local e internacional. A autora destacou cinco forças globais que sustentam o modelo de EC implantado: o surgimento da educação por processos, a partir da melhoria contínua; a emergência da gestão do conhecimento; a volatilidade e obsolescência das informações e do conhecimento; o foco na educação para o trabalho e não para o emprego; e a mudança no foco da educação geral.

Para Eboli (2002), a educação corporativa manifesta-se como uma solução para o desenvolvimento de pessoas capazes de refletir criticamente sobre a realidade organizacional, propondo modificações constantes em favor da competitividade. Logo, para a autora, a Educação Corporativa não é um processo em si, mas sim, uma ferramenta estratégica, alinhada aos objetivos com os resultados pretendidos, voltada para a criação e evolução de competências organizacionais e profissionais, objetivando uma visão que parte do princípio da coletividade e do foco da atividade (Eboli, 2004; 2008).

Seguindo este objetivo, houve a alteração dos perfis profissionais procurados, de maneira contínua. Nessa direção, Meister (1999) apresenta sete competências cada vez mais pleiteadas pelas organizações:

Quadro 1 - Competências profissionais desejadas.

\begin{tabular}{|l|l|}
\hline Competências & Conceitos \\
\hline Aprender a aprender & $\begin{array}{l}\text { Capacidade de, a cada experiência e conhecimento adquiridos, sejam estes } \\
\text { profissionais ou pessoais, desenvolver uma aprendizagem contínua. }\end{array}$ \\
\hline $\begin{array}{l}\text { Comunicação } \\
\text { colaboração e }\end{array}$ & $\begin{array}{l}\text { Habilidades e competências de comunicação e colaboração, de trabalho em equipe, } \\
\text { não são mais vistas como diferenciais, mas sim como quesitos obrigatórios aos } \\
\text { profissionais atuais. }\end{array}$ \\
\hline $\begin{array}{l}\text { Raciocínio criativo e } \\
\text { solução de problemas }\end{array}$ & $\begin{array}{l}\text { Habilidade de conceder respostas rápidas e construtivas aos clientes e ao mercado } \\
\text { através de um pensamento criativo, autônomo e de liderança. }\end{array}$ \\
\hline $\begin{array}{l}\text { Conhecimento } \\
\text { tecnológico }\end{array}$ & Atenção às mudanças tecnológicas e integração ao mundo virtual. \\
\hline $\begin{array}{l}\text { Conhecimento de } \\
\text { negócios globais }\end{array}$ & $\begin{array}{l}\text { Conhecimento da cultura local e dos locais em que se deseja fazer negócios, } \\
\text { procurando agregar valor à organização e preencher os requisitos legais. }\end{array}$ \\
\hline Desenvolvimento de & Trabalhar como agentes ativos da mudança, encorajar a autonomia. \\
\hline
\end{tabular}

R.G. Secr., GESEC, São Paulo, v. 9, n. 1, p 108-127, jan./abr. 2018. 


\begin{tabular}{|l|l|}
\hline liderança & \\
\hline $\begin{array}{l}\text { Autogerencimento da } \\
\text { carreira }\end{array}$ & $\begin{array}{l}\text { Autogerenciar a carreira para atender seus objetivos pessoais e profissionais, assim } \\
\text { como atender a demanda local e futura das habilidades e competências em relação às } \\
\text { organizações. }\end{array}$ \\
\hline
\end{tabular}

Fonte: Adaptado de Antonini e Saccol (2010).

A fim de se alcançar esse novo perfil profissional, as organizações devem não apenas buscar o conhecimento técnico para exercer atividades operacionais, mas privilegiar a aquisição de habilidades, comportamentos e atitudes que são interessantes à estratégia. Os profissionais devem ser estimulados a apresentar comportamentos voltados à aprendizagem contínua e ao autodesenvolvimento (Eboli, 2002; Meister, 1999). Porém, deve ser levado em consideração que a EC não é voltada apenas para agir em pessoas, mas em conjunto com os processos, pautada em criar uma cultura de alto desempenho e na busca por resultados (Eboli, 2002).

Também sobre essas tendências e esse compromisso das organizações com a educação levam ao desenvolvimento de todos os envolvidos e a geração de valor para as organizações que ajudam a alcançar um novo estágio na criação de uma competitividade sustentável. Meister (1999) já apontava para este fenômeno ao afirmar que se tornava evidente que a Educação Corporativa é um eficaz portador e transmissor de alinhamentos pautados no desenvolvimento e transformação de gestão de pessoas de acordo com as estratégias e, ao fazer uma reflexão deste novo modelo de educação, chega-se à conclusão de que, em geral, os profissionais lançados ao mercado pelas instituições tradicionais de ensino, assim como os formados se treinados, não possuem em seus devidos processos de treinamento e desenvolvimento esta perspectiva.

Por fim, as técnicas e procedimentos estratégicos da Educação Corporativa devem objetivar o desenvolvimento do indivíduo de maneira integral e com ferramentas que deem a capacidade de disseminação do conhecimento e de atribuir inovação e criatividade às atividades e produtos inerentes às organizações. A partir deste momento, são instituídas as chamadas Universidades Corporativas que, para Eboli (2004, 2008), são a transição de um modelo tradicional e técnico de treinamento e desenvolvimento, para um modelo mais amplo que é voltado para a educação integral. Para o sucesso da implantação de um modelo de educação corporativa, a autora sugere sete princípios básicos: "Competitividade, perpetuidade, conectividade, disponibilidade, cidadania, parceria e sustentabilidade".

Quadro 2 - Princípios para o sucesso da Educação Corporativa segundo Eboli (2004).

R.G. Secr., GESEC, São Paulo, v. 9, n. 1, p 108-127, jan./abr. 2018. 
Toledo, G. S. \& Domingues, C. R. (2018).

\begin{tabular}{|l|l|}
\hline Princípios & Conceito \\
\hline Competitividade & $\begin{array}{l}\text { Educação como forma de desenvolvimento de capital intelectual, transformando-o em } \\
\text { vantagem competitiva. Desenvolvimento de competências críticas. }\end{array}$ \\
\hline Perpetuidade & $\begin{array}{l}\text { Líderes e gestores como responsáveis pela transmissão e perpetuidade da cultura do } \\
\text { conhecimento. }\end{array}$ \\
\hline Conectividade & $\begin{array}{l}\text { Integração entre a gestão e o conhecimento, interação dos profissionais para troca de } \\
\text { experiências, qualidade na rede de relacionamento externos e internos. }\end{array}$ \\
\hline Disponibilidade & $\begin{array}{l}\text { Fácil acesso à educação por meio de métodos de ensino/aprendizagem contínuos } \\
\text { eficazes. }\end{array}$ \\
\hline Cidadania & $\begin{array}{l}\text { Integração entre projetos educacionais e sociais, ações pautadas na ética e na } \\
\text { responsabilidade social. }\end{array}$ \\
\hline Parceria & $\begin{array}{l}\text { Parceria internas e externas, entre líderes e gestores e instituições de ensino, } \\
\text { respectivamente. }\end{array}$ \\
\hline Sustentabilidade & $\begin{array}{l}\text { Busca por processos e competências que garantam a perenidade e sustentabilidade } \\
\text { financeira e social dos negócios. }\end{array}$ \\
\hline
\end{tabular}

Fonte: Adaptado de Moura, Galhano e Polo (2006).

O quadro explicita os princípios que segundo Eboli (2004), formam os principais elementos para que a Educação Corporativa tenha efetividade. Ao elencar cada um deles torna-se evidente que estão todos imbricados, logo, são interdependentes e sua sustentação se dá por meio de estratégias de longo prazo e com o perene apoio da alta cúpula. Sem contar que deve ser estimulada a participação de todos os agentes organizacionais na sua consecução.

\section{Procedimentos Metodológicos}

Este artigo tem como principal característica a pesquisa de caráter bibliométrico. Uma técnica desenvolvida no início do século XX como uma reação à necessidade de estudos e avaliações de produções científicas (Marcelo \& Hayashi, 2013; Fonsceca, 2006). A bibliometria é uma técnica quantitativa e estatística que visa medir elementos da produção científica "[...] tal como procede a demografia ao recensear a população" de acordo com Fonseca (1986, p. 10).

O estudo bibliométrico deixa de lado os julgamentos de valor para se dispor de um banco de dados que tem por objetivo informar sobre o número de autores, trabalhos, países, revistas, periódicos, temas, linhas de pesquisa, entre outros (Price apud Marcelo \& Hayashi, 2013).

Especificamente para os estudos bibliométricos, é preciso atender às leis que foram desenvolvidas para a condução sistêmica deste modelo de estudo. São elas as leis de Bradford, Zipf e Lotka: a Lei de Bradford, também conhecida como Lei da Dispersão dos Periódicos, tem como objetivo avaliar qual o grau de atração e de relação de estudos e 
periódicos de acordo com determinadas temáticas. A Lei de Zipf busca analisar o número de ocorrências das palavras-chaves em diversos textos de uma determinada temática, identificando qual a linha de pesquisa tratada nessas publicações. Por fim, a lei desenvolvida por Lotka, conhecida como Lei do Quadrado Inverso, tem por objetivo criar um banco de dados capaz de proporcionar um modelo de distribuição de frequências e quantidades de autores e publicações num determinado tema e período (Moretti \& Campanario, 2009). Tais elementos foram a base para se realizar a análise dos dados depois destes serem organizados e são sintetizados e apresentados no Quadro 3:

Quadro 3 - Leis que regem os estudos bibliométricos.

\begin{tabular}{|l|l|l|l|}
\hline Leis & Medida & Critério & Objetivo Geral \\
\hline Lei de Bradford & $\begin{array}{l}\text { Grau de atração do } \\
\text { periódico }\end{array}$ & $\begin{array}{l}\text { Reputação do } \\
\text { periódico }\end{array}$ & $\begin{array}{l}\text { Identificar os periódicos mais relevantes e } \\
\text { que dão maior vazão a um tema em } \\
\text { específico. }\end{array}$ \\
\hline Lei de Zipf & $\begin{array}{l}\text { Frequência de } \\
\text { palavras-chave }\end{array}$ & $\begin{array}{l}\text { Lista ordenada de } \\
\text { temas }\end{array}$ & $\begin{array}{l}\text { Estimar os temas mais recorrentes } \\
\text { relacionados a um campo de conhecimento. }\end{array}$ \\
\hline Lei de Lotka & Produtividade autor & $\begin{array}{l}\text { Tamanho- } \\
\text { frequência }\end{array}$ & $\begin{array}{l}\text { Levantar o impacto da produção de um autor } \\
\text { numa área de conhecimento. }\end{array}$ \\
\hline
\end{tabular}

Fonte: Elaborado pelos autores.

Do ponto de vista da natureza, esta pesquisa se caracteriza como básica, pois objetiva criar conhecimentos sem previsão de aplicação prática (Gil, 2016). A pesquisa é de abordagem quantitativa, pois se pretende colher informações para traduzi-las em números para que seja possível classificá-las e analisá-las.

O objetivo deste artigo foi, a partir de um levantamento bibliográfico, identificar e analisar o que se tem produzido a respeito do tema Educação Corporativa, assim como as características desta produção acadêmica. Para tanto, foi realizado um levantamento dos principais repositórios de artigos brasileiros e optou-se pelo que, além de ter em seu banco artigos de defesas de dissertações e teses, também fossem ligados aos mais importantes eventos voltados à administração e gestão, oferecendo à pesquisa maior possibilidade de localizar, acessar, triar e analisar as produções. Assim, foram pesquisados os trabalhos acadêmicos por meio das plataformas Portal SPELL, Capes e demais periódicos ligados a Anpad, como a BAR - Brazilian Administration Review, a RAC - Revista de Administração Contemporânea, a TAC-Tecnologia de Administração e Contabilidade e a RAC Eletrônica.

Para realizar a pesquisa nessa base de dados foram utilizados os termos relacionados aos macrotemas: Estratégia e Conhecimento; Gestão do Conhecimento; Inteligência Coletiva; 
Toledo, G. S. \& Domingues, C. R. (2018).

Capacidade Absortiva; Liderança e Desenvolvimento Gerencial; Políticas, Modelos e Práticas de Gestão de Pessoas; Aspectos Sociais, Culturais e Comportamentais dos Sistemas de Informação; Teoria e Práticas de Gestão de Pessoas; Gestão por Resultados versus Gestão de Pessoas; Estratégia em Organizações; Gestão de Pessoas. E como palavras-chaves: gestão do treinamento; treinamento e desenvolvimento; recurso de treinamento e desenvolvimento; treinamento e desenvolvimento gerencial; aprendizagem organizacional, educação corporativa e gestão por competências.

Foram encontrados 31 artigos, sendo todos eles utilizados e dos quais foram extraídos os dados referentes a: ano de publicação, periódico, título, autores, instituição de ensino, objetivo, palavras-chaves, tema, citações, abordagem, tipo de pesquisa, objetivos (exploratória, descritiva ou explicativa), procedimentos técnicos, tema e subtema e obras utilizadas. Depois de levantados, esses dados foram salvos em planilhas do Microsoft Excel para melhor visualização e organização e para que posteriormente fossem analisados com a ajuda de uma tabela dinâmica.

\section{Análise dos Dados}

Para atender ao objetivo de uma pesquisa bibliométrica, é necessário coletar os dados e apresentar os resultados à luz das três leis que a sustentam. Assim, a análise dos dados se deu a partir do uso do software Excel e seus comandos de funções estatísticas, bem como pelo uso da função tabela dinâmica e teve como pano de fundo as Leis de Bradford, Zipf e Lotka. Ao realizar tais tratamentos foi possível realizar as análises que são apresentadas a seguir.

De acordo com o Gráfico 1, observa-se que a distribuição das publicações referentes ao tema pesquisado é relativamente constante, na qual em metade dos anos em que houve publicações, tem-se de três a quatro artigos, destacando-se o período de 2010 a 2014. Nota-se a linha de tendência crescente durante os anos e, seguindo esta linha, o número de publicações cresce até 2014. Porém, nos dois próximos anos, os trabalhos relativos ao tema retornam aos níveis dos primeiros anos levados em consideração neste estudo. 


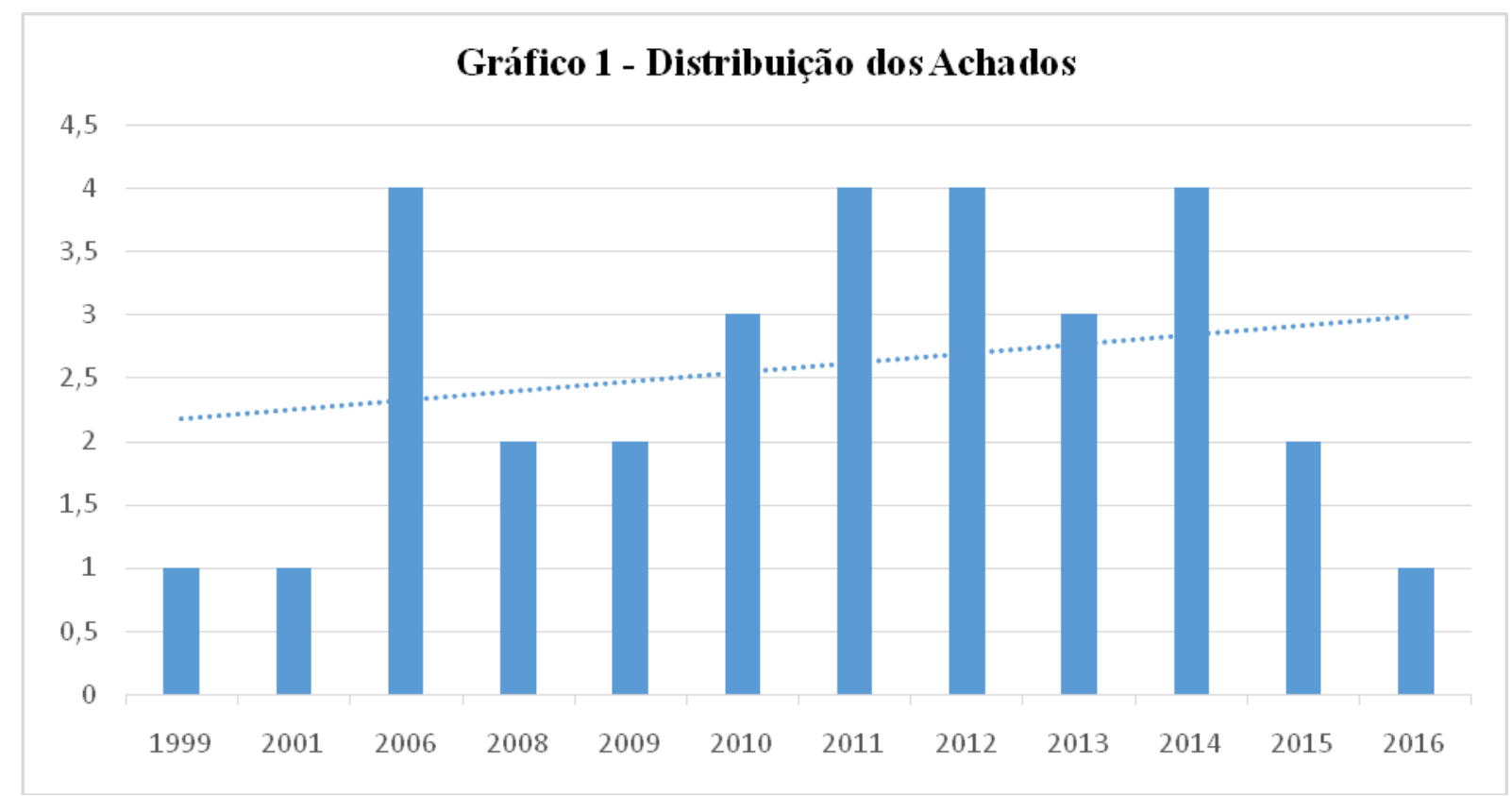

Fonte: dados da pesquisa.

Observa-se claramente a predominância de artigos publicados em parceria, representando $84 \%$ das obras, principalmente com dois autores, representados por $45 \%$ das publicações (Gráfico 2). Esses dados reafirmam o fato de que as pesquisas acadêmicas são, em sua grande maioria, desenvolvidas em parceria com o objetivo de proporcionar maior rendimento das publicações e a difusão entre áreas do conhecimento.

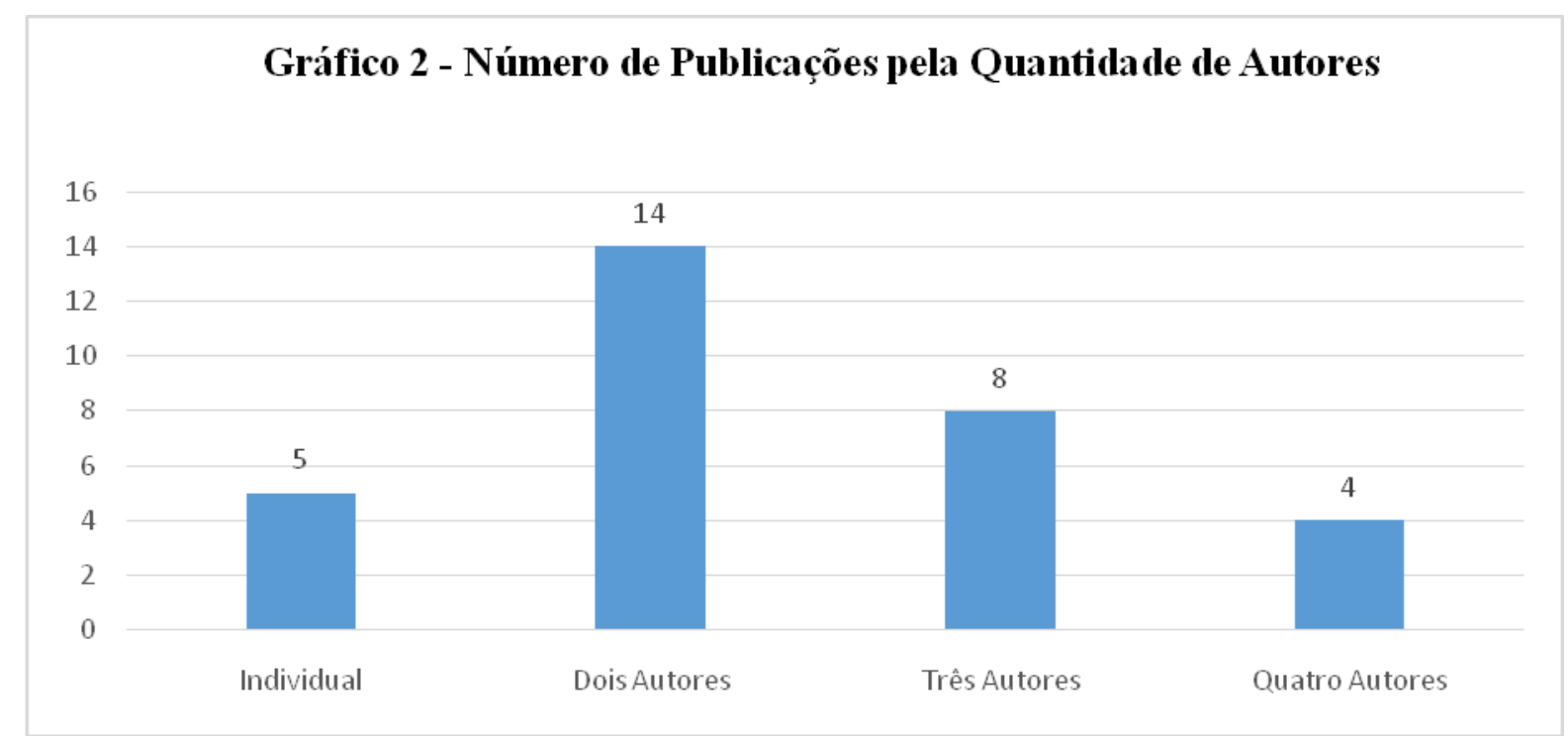

Fonte: dados da pesquisa.

O Gráfico 3 apresenta os autores que mais tiveram artigos publicados no período pesquisado. Destaca-se Marisa Pereira Eboli com sete publicações, que representa $23 \%$ do 
Toledo, G. S. \& Domingues, C. R. (2018).

total. Porém, cabe destacar ainda, Amarolinda Zanela Klein e Flávio Hourneoux Júnior, cada um com quatro publicações e Carolina Aparecida de Freitas Dias, com três publicações.

Ainda no Gráfico 3, chama atenção a quantidade de autores que publicaram apenas uma vez, dos 54 autores observados tivemos o total de 45 com apenas uma publicação, o que representa $83 \%$ dos autores. Esse dado evidencia que poucos autores desenvolvem muito e muitos autores desenvolvem poucos trabalhos acadêmicos sobre temas de uma mesma linha de atuação.

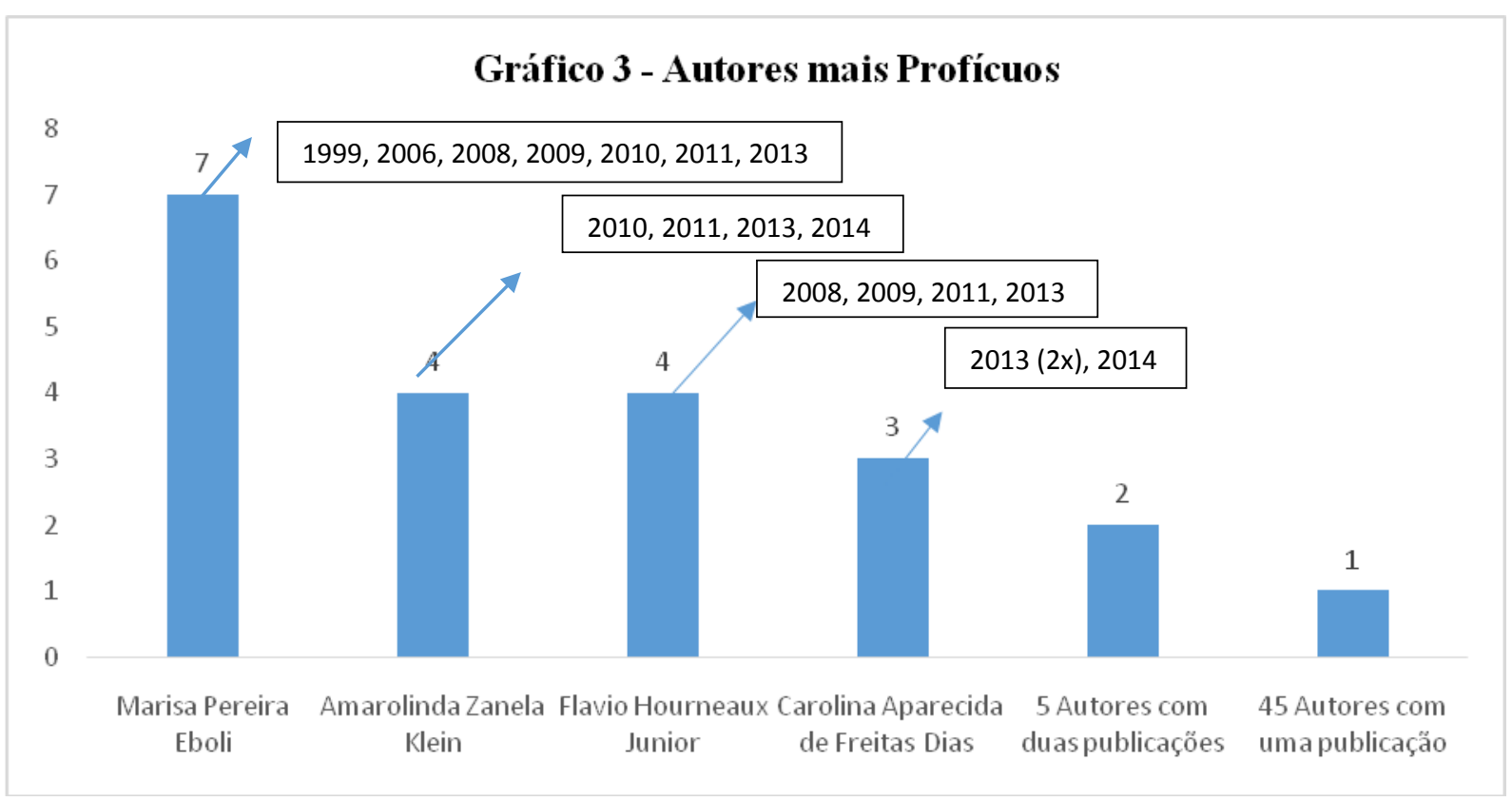

Fonte: dados da pesquisa.

A autora Marisa Pereira Eboli teve seu primeiro trabalho publicado, em sua respectiva linha de atuação, em 1999, sendo um trabalho de autoria individual e ainda o primeiro trabalho encontrado nos periódicos pesquisados a respeito da Educação Corporativa. É possível destacar, também, a participação de Marisa Pereira Eboli nas publicações em parceria com outros dois autores mais profícuos, com Flávio Hourneaux Júnior, o qual teve seus quatro artigos publicados em parceria com Eboli e com Carolina Aparecida de Freitas Dias, uma publicação. Com exceção da primeira publicação de Eboli, todos os demais autores mais profícuos desenvolveram seus trabalhos em parceria com, pelo menos, mais um autor. $\mathrm{O}$ nível baixo de integração entre os demais autores pesquisados pode ser reflexo de um campo de estudo novo e ainda pouco explorado nas universidades e organizações brasileiras.

O Quadro 3 apresenta a linha de atuação dos autores que mais publicaram. Com exceção de Amarolinda Zanela Klein, os demais autores mais profícuos desenvolvem projetos 
na linha de atuação "Políticas, Modelos e Práticas de Gestão de Pessoas", justificando a parceria entre eles em publicações. Observa-se também, que as demais linhas de atuação desses autores (gestão do conhecimento, liderança e desenvolvimento gerencial, gestão do conhecimento e gestão por resultados) estão intimamente ligados aos conceitos de Educação Corporativa citados no referencial teórico e objeto de estudo deste artigo. Em observação mais ampla, as linhas de atuação remetem aos temas abordados nos artigos pesquisados.

Ainda segundo o Quadro 3, pode-se identificar que a linha de atuação, de acordo com a Anpad, dos autores mais profícuos vai ao encontro com a linha de pesquisa declarada em seus respectivos currículos Lattes. Isso permite afirmar que não são autores meramente especulativos dentro do tema.

Quadro 3 - Linha de atuação dos autores mais profícuos.

\begin{tabular}{|c|c|c|}
\hline Autor & $\begin{array}{l}\text { Linha de Pesquisa da Publicação } \\
\text { segundo a Anpad }\end{array}$ & Linha de Pesquisa - Lattes \\
\hline \multirow{2}{*}{ Marisa Pereira Eboli } & $\begin{array}{l}\text { Políticas, Modelos e Práticas de } \\
\text { Gestão de Pessoas }\end{array}$ & \multirow{2}{*}{$\begin{array}{l}\text { Gestão de Pessoas nas } \\
\text { organizações. }\end{array}$} \\
\hline & Gestão de Pessoas & \\
\hline \multirow[b]{2}{*}{ Amarolinda Zanela Klein } & Gestão do Conhecimento & Estratégias Organizacionais \\
\hline & $\begin{array}{l}\text { Liderança e Desenvolvimento } \\
\text { gerencial }\end{array}$ & $\begin{array}{l}\text { Competitividade e Sistemas de } \\
\text { Informação }\end{array}$ \\
\hline \multirow{2}{*}{ Flávio Hourneaux Júnior } & $\begin{array}{l}\text { Gestão por Resultados versus } \\
\text { Gestão de Pessoas }\end{array}$ & $\begin{array}{lll}\text { Gestão do } & \text { Desempenho } \\
\text { Organizacional } & \\
\end{array}$ \\
\hline & $\begin{array}{l}\text { Políticas, Modelos e Práticas de } \\
\text { Gestão de Pessoas }\end{array}$ & Gestão da Sustentabilidade \\
\hline Carolina Aparecida de Freitas Dias & $\begin{array}{l}\text { Políticas, Modelos e Práticas de } \\
\text { Gestão de Pessoas }\end{array}$ & $\begin{array}{l}\text { Gestão Estratégica de Pessoas; } \\
\text { Gestão da Educação Corporativa; } \\
\text { Gestão do Conhecimento nas } \\
\text { Organizações. }\end{array}$ \\
\hline
\end{tabular}

Fonte: dados da pesquisa.

O Gráfico 4 destaca os autores mais citados nos artigos publicados que foram investigados. Estabelece-se a relação de que a autora que mais publica também é a referência mais citada quando se trata de Educação Corporativa. Ao todo foram 43 citações nos 31 artigos publicados. Observa-se também a dominância de Marisa Pereira Eboli e Jeanne C. Meister, citadas ao todo 73 vezes. Paralelo a isso é cabível destacar as obras mais citadas dessas duas autoras, que podem ser visualizadas no Quadro 4.

Quadro 4 - Obras mais citadas.

Eboli, M. (2004) Educação Corporativa no Brasil: Mitos e verdades. São Paulo: Editora Gente.

Meister, J. C. (1999) Educação Corporativa: a gestão do capital intelectual através das universidades corporativas. Tradução de Maria Claudia Santos Ribeiro Ratto. São Paulo: Makron Books.

Fonte: dados da pesquisa.

R.G. Secr., GESEC, São Paulo, v. 9, n. 1, p 108-127, jan./abr. 2018. 
Toledo, G. S. \& Domingues, C. R. (2018).

Vale destacar as referências aos autores J. E Andrade, M.T Fleury e H. Mintzberg. Estes autores têm a linha de atuação focada na Estratégia Organizacional, disciplina que foi pontualmente citada nos artigos para se relacionar com a Educação Corporativa. Esta constatação nos mostra a tendência a qual as áreas de Recursos Humanos das organizações devem seguir, buscando serem trabalhadas como um RHs Estratégicos e estando intimamente integradas com os objetivos da organização, deixando de ser vistas como áreas operacionais e que não fornecem diferenciais competitivos.

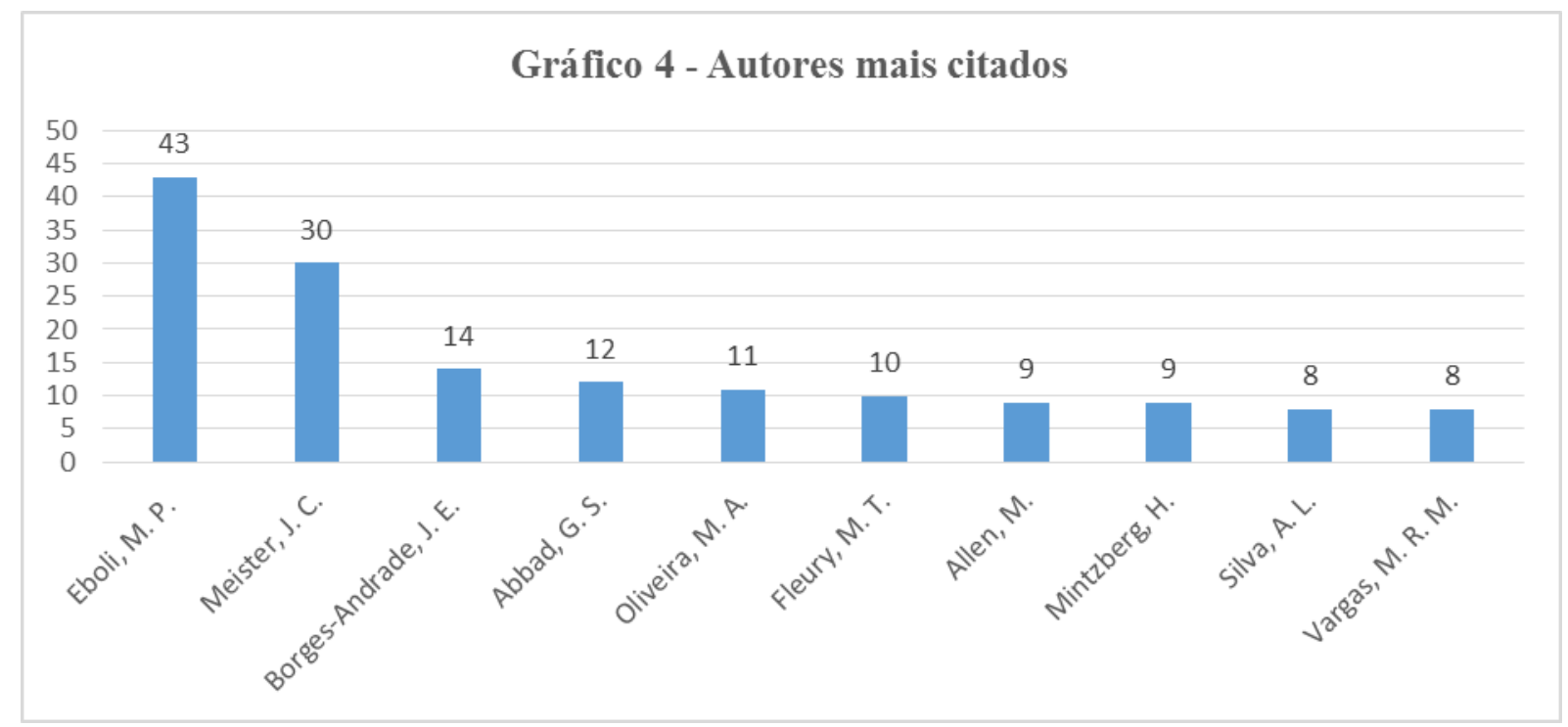

Fonte: dados da pesquisa.

Em relação às Instituições de Ensino Superior que mais publicam, o Gráfico 5 evidencia a realidade nacional, a Universidade de São Paulo (USP) é claramente a que possui mais autores publicando, com 20 participações, seguida de longe pela Unisinos com seis. A hegemonia da USP é clara. Vale ressaltar que dos 31 artigos investigados, foram observados autores ligados à USP em 10 publicações diferentes, sendo em oito delas apenas com autores da instituição de ensino paulista, em publicações cooperadas ou não. Em seguida observaramse UnB e FEI com quatro participações; FPL com três; UFRJ, FGV, FIA e UFAM com duas e UFPE, Universidade Positivo, Uninove e UFMG com uma participação.

Um fato interessante é que instituições como FGV, UFRJ, UnB e UFMG, que são tidas como referências nas áreas de administração, ciências sociais e em estudos organizacionais, eram poucas pesquisas e/ou publicações que instituições menos ranqueadas. 


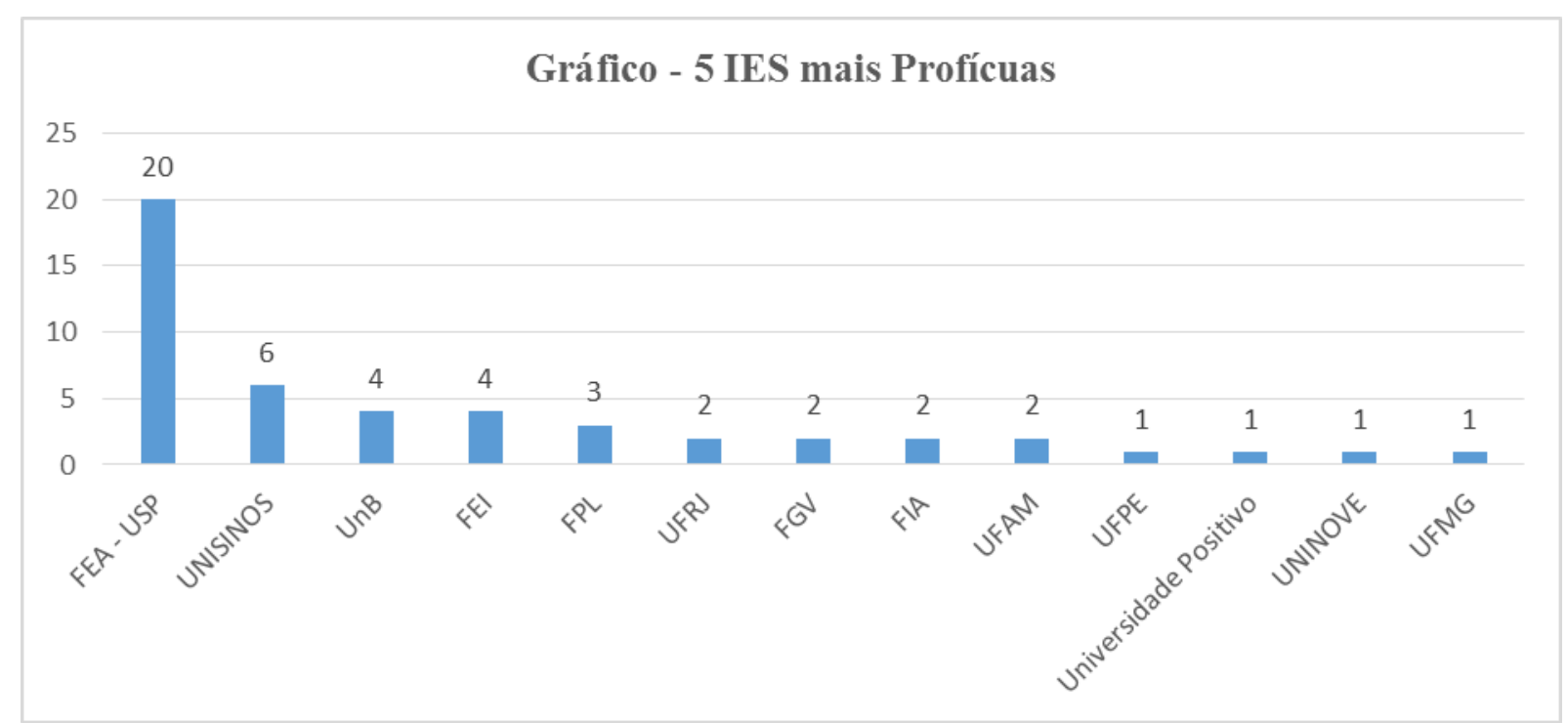

Fonte: dados da pesquisa.

Constatou-se, também, que os artigos publicados em coautoria são contemplados em sua maioria por autores de uma única IES. Apenas $22 \%$ dos artigos analisados possuíam autores de diferentes instituições.

\section{Gráfico 6 - Abordagem Metodológica}

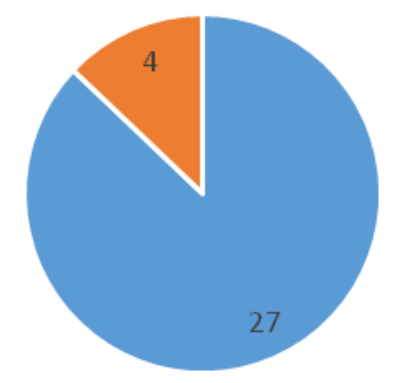

- Qualitativo = Quantitativo

Fonte: dados da pesquisa.

De acordo com o Gráfico 6, dos 31 artigos analisados, 27 possuem abordagem qualitativa, predominando em todos os anos pesquisados e verificando-se que os artigos procuravam por um aprofundamento teórico do tema. Paralelo a isto, observou-se um equilíbrio claro entre as tipologias de estudo, em que 11 artigos declaravam ser de caráter exploratório, 14 descritivos e seis descritivos e exploratórios, como destacado no Gráfico 8. 
Toledo, G. S. \& Domingues, C. R. (2018).

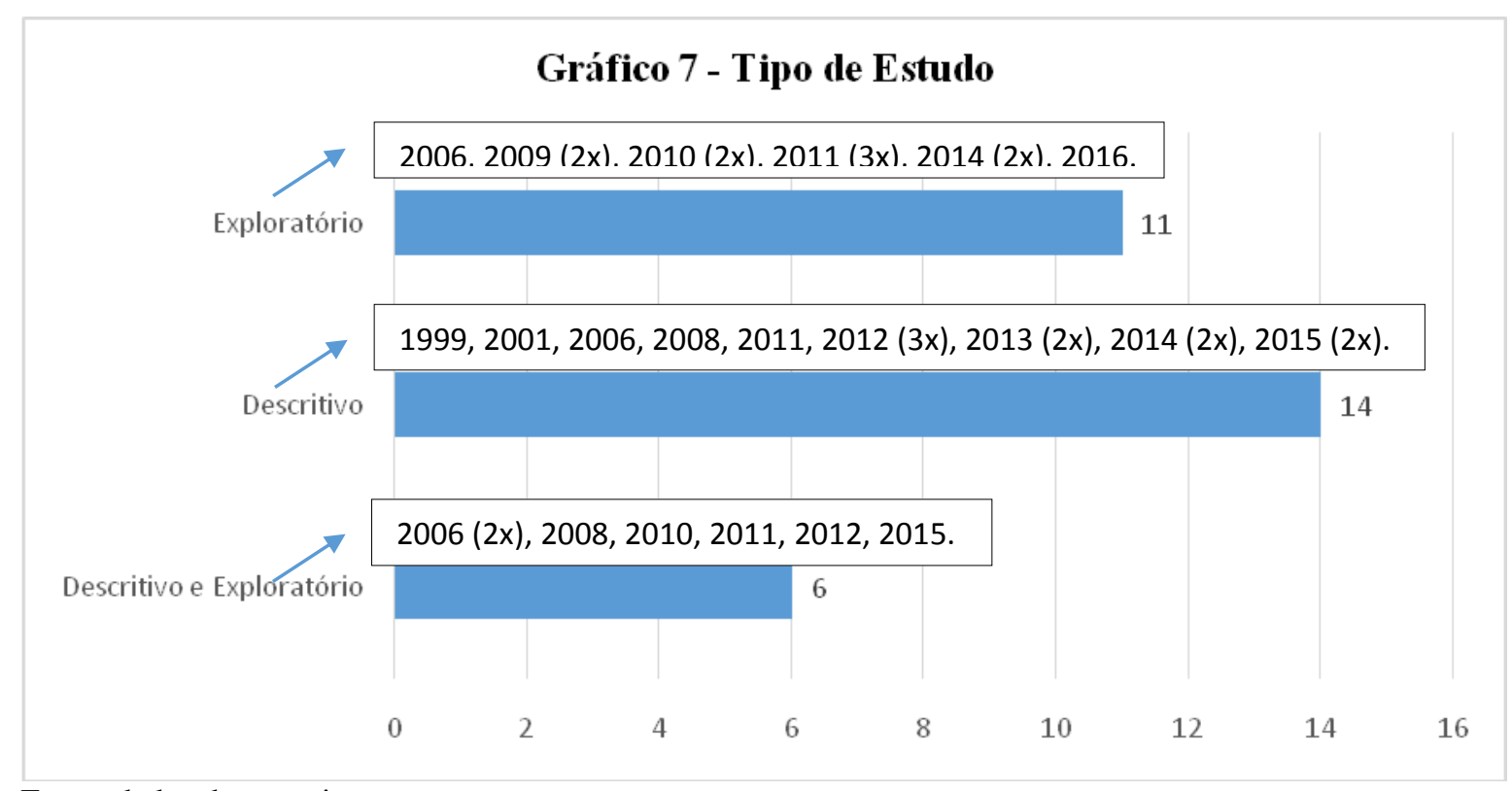

Fonte: dados da pesquisa.

Para complementar os Gráficos 6 e 7, constata-se a Análise de Conteúdo como a principal técnica de pesquisa, por meio da análise de documentos e de bibliografias. A Pesquisa de Campo também foi muito abordada, utilizando entrevistas e questionários como principais ferramentas de coleta de dados.

Por fim, contemplando as palavras-chave mais utilizadas e citadas nos artigos pesquisados, destacam-se: Educação, Corporativa, Aprendizagem, Treinamento, Estratégico, Organizacional, Conhecimento, Gestão e Desenvolvimento. Como esperado, as palavras remetem ao objeto de estudo que é a Educação Corporativa e também suas principais relações: a área de Treinamento e Desenvolvimento, a Gestão de Pessoas e a Estratégia Organizacional.

As Figuras 2, 3 e 4 representam uma linha do tempo relacionando os objetivos gerais de cada artigo selecionado aos anos de publicação. Podemos observar que nos oito primeiros anos nos quais houve publicações, pelo menos um artigo ao ano foi publicado com o objetivo de se identificar e analisar os principais desafios, resistências, limitações e responsabilidades inerentes à implantação das práticas de Educação Corporativa nas organizações.

A partir de 2013, os objetivos passam a ter outro foco, agora voltado para avaliações de resultados das práticas adotadas as organizações, bem como quais eram as ferramentas de avaliação utilizadas. Observa-se também, neste intervalo de quatro anos, a relação estabelecida entre a Educação Corporativa como geradora de produtividade qualitativa e quantitativa e como grande influenciadora do desempenho organizacional.

R.G. Secr., GESEC, São Paulo, v. 9, n. 1, p 108-127, jan./abr. 2018. 
Apesar de muitos desses objetivos representados pelas Figuras 2, 3 e 4 estarem apresentando as palavras "análise" e "avaliação", sugerindo que são estudos analíticos/explicativos, em nenhuma das metodologias dos 31 artigos analisados eles foram citados como tal. Tal fato deixa explícita uma contradição entre o modo em que os autores desejam realizar seus estudos, modo em que estes descrevem em suas respectivas metodologias de pesquisa, e a maneira de que de fato é desenvolvida. As pesquisas explicativas de acordo com Gil (2016, p. 28), têm como principal preocupação identificar os fatores determinantes ou que contribuem para que um fenômeno ocorra, sendo um tipo de pesquisa que busca aprofundar o conhecimento da realidade explicando o porquê das coisas e por isso tende a ser complexo e delicado com alto risco de erros.

Portanto, a partir da análise em conjunto de todos os dados levantados, pode-se afirmar que a pesquisa vai ao encontro com que os principais autores do tema Educação Corporativa e Gestão de Pessoas têm afirmado em suas obras contemporâneas. As áreas de Recursos Humanos dentro das organizações vêm deixando de ser meras coadjuvantes e desfrutadoras de recursos financeiros, para finalmente terem seus valores estratégicos reconhecidos e assim serem trabalhadas como tais. Os estudos reforçam, cada vez mais, que a gestão dos recursos humanos, desde que bem definido seu papel e alinhamento com a estratégia, pode gerar uma elevada taxa de variação positiva de desempenho organizacional e produtividade.

\section{Considerações Finais}

Por meio deste estudo bibliométrico, representado pelos 31 artigos selecionados a partir das bases de dados SPELL, Capes e dos eventos da Anpad nos últimos vinte anos, conclui-se que o tema está em ascensão apesar da ainda pequena quantidade de estudos, de observações práticas nas organizações brasileiras e do fato de os últimos dois anos o número de publicações não ter seguido a linha de tendência destacada no Gráfico 1.

Destaca-se a identificação de Marisa Pereira Eboli, doutora pela Universidade de São Paulo, como a predecessora do tema Educação Corporativa no Brasil. Além de ser a autora que mais contribuiu com publicações de artigos acadêmicos, também foi a autora mais citada nas obras brasileiras analisadas, por meio do seu trabalho "Educação Corporativa: Mitos e verdades (2004) ". 
Toledo, G. S. \& Domingues, C. R. (2018).

Destaca-se também que $84 \%$ das obras publicadas foram desenvolvidas em parceria, salientando que três dos quatro autores mais profícuos publicaram obras como coautores. Esse fato é justificado pela busca de maior rendimento das publicações e troca de experiências em diversas áreas do conhecimento. Nesse caso, destacamos Flávio Hourneaux Júnior como "herdeiro" dos conceitos publicados por Marisa. No caso de Flávio, suas quatro obras foram publicadas em coautoria com ela. Porém, os quatro autores mais profícuos deixaram de publicar obras sobre o tema a partir dos anos de 2013/2014, sendo a concentração das publicações destes autores entre os anos de 2008 e 2014.

Nesse contexto, no qual quatro autores dominam em quantidade de publicações e outros 50 autores publicam pouco (destes, 45 apenas uma vez), identifica-se a confirmação da Lei de Lotka, a qual afirma que poucos autores publicam muito e muitos autores publicam pouco sobre determinado tema.

Nos últimos cinco anos, observa-se um aumento considerável de publicações sobre o tema, com o seguinte ponto de atenção: é possível dividir o estudo em dois momentos distintos, de 1999 a 2012 e de 2013 a 2016.

No primeiro intervalo identifica-se que os objetivos dos estudos estavam voltados para um momento de implantação e análise do tema. Nesse intervalo destacamos o início das aplicações de modelos de Educação Corporativa, baseando-se em pesquisas cujo objetivo era o de identificar os principais desafios, limitações e resistências a eles.

Já no segundo intervalo, evidencia-se a ascensão das pesquisas focadas nos resultados desses modelos que foram implantados efetivamente em determinadas organizações, destacando-se as de atividades financeiras e de tecnologia da informação. Nesse caso, identifica-se um momento de manutenção do tema e colheita dos resultados da implantação.

É necessário, também, dar atenção ao movimento que a área dos Recursos Humanos tende a seguir, nestes estudos, para as disciplinas de Estratégia. Justifica-se tal movimento pelo fato de que dentre os autores mais citados nas obras também temos J. E Andrade, H. Mintzberg e M.T Fleury, que são acadêmicos desta última disciplina. Além disso, observa-se o uso de palavras-chave como as derivadas de "estratégia", "informação" e "missão" nos artigos estudados. Neste último caso, observa-se também a Lei de Zipf sobre a frequência de palavras chave em outros temas relacionados com o estudo. Neste estudo em si, o relacionamento da Educação Corporativa com a Estratégia. 
Destaca-se como principal dificuldade na elaboração deste estudo a quantidade limitada de conteúdo e autores experientes quando o tema é Educação Corporativa no Brasil, o qual não possui uma sequência de estudos e limita uma análise mais profunda da evolução do tema no país, seja acadêmico ou nas organizações. A partir disso, sugere-se um estudo abordando artigos e publicações internacionais para identificar o que está sendo trabalhado em outros países e qual o estágio da EC nas organizações multinacionais.

Portanto, este artigo permitiu estudar a evolução dos estudos sobre Educação Corporativa no país, assim como sua tendência e seu relacionamento com outros campos do conhecimento, principalmente com a Estratégica Organizacional. Logo os dados aqui apresentados podem instrumentalizar e sugerir novas pesquisas futuras.

\section{Referências}

Albertin, A. L., \& Brauer, M. (2012 set./out.). Resistência à educação a distância na educação corporativa. Rev. Adm. Pública, Rio de Janeiro: set./out.

Albuquerque, L. G., \& Fischer, A. L. (2000). Pesquisa RH 2010: uma análise das tendências em gestão de pessoas para os próximos 10 anos. São Paulo: FIA/FEA-USP.

Albuquerque, L. G., \& Oliveira, P. M. (2001). Competências ou cargos: uma análise das tendências das bases para o instrumental de recursos humanos. Caderno de Pesquisas em Administração, São Paulo, 8 (4), out/dez.

Antonini, L. S., \& Saccol, A. I. C. Z. (2010). Desafios enfrentados por pequenas e médias empresas do setor de software nos seus processos de educação corporativa. Enanpad Encontro Nacional dos Programas de Pós-graduação em Administração, Rio de Janeiro.

Eboli, M. (1999, out.,/dez.). Universidade corporativa: ameaça ou oportunidade para as escolas tradicionais da administração? Revista de Administração, 34(4), pp. 56-64, out./dez.

(2002). O desenvolvimento das pessoas e a educação corporativa. In Fleury, M. T. (org.) As pessoas na organização. São Paulo: Editora Gente.

. (2004). Educação corporativa no Brasil: mitos e verdades. São Paulo: Gente. 
Toledo, G. S. \& Domingues, C. R. (2018).

Eboli, M., Horneaux Júnior, F., \& Cassimiro, W. T. (2008). Educação corporativa: governança, dinâmica e estrutura das universidades corporativas no Brasil. ENGPR Encontro Nacional de Gestão de Pessoas, João Pessoa.

Fonseca, E, N. (Org). (1986). Bibliometria: teoria e prática. São Paulo: Cultrix, Ed. da USP.

Gil, A. C. (2016) Métodos e técnicas de pesquisa social (6a ed.). São Paulo: Atlas.

Marcelo, J. F., \& Hayashi, M. C. P. I. (2013, set./dez.). Estudo bibliométrico sobre a produção científica no campo da sociologia da ciência. Revista UEL, 18(3), pp. 138-153, set./dez.

Meister, J. C. (1999). Educação corporativa: a gestão do capital intelectual através das universidades corporativas. São Paulo: Makron Books.

Moscardini, T. N., \& Klein, A. Z. (2015, março). Estratégias de educação corporativa e suas relações com os diferentes níveis de aprendizagem organizacional. Rev. Adm. UFSM, 8, pp. 89-102, mar.

Moretti, S. L. A., \& Campanario, M. de A. (2009). A produção intelectual brasileira em responsabilidade social empresarial - RSE sob a ótica da bibliometria. Revista de Administração Contemporânea, Edição Especial, 13, pp. 68-86.

Moura, G. L., Galhano, P. P. P., \& Polo, E. F. (2006). Organização estratégica e educação corporativa. Enanpad - Encontro Nacional dos Programas de Pós-graduação em Administração, Salvador.

R.G. Secr., GESEC, São Paulo, v. 9, n. 1, p 108-127, jan./abr. 2018. 